\title{
Exploring differences in quality of life in clinical populations of depressed outpatients with and without personality disorders
}

Citation for published version (APA):

Kool, M., Lemmens, L. H. J. M., Hartog, P., Van, R., Blankers, M., Peen, J., van Bronswijk, S. C., \& Dekker, J. J. M. (2021). Exploring differences in quality of life in clinical populations of depressed outpatients with and without personality disorders. Journal of Affective Disorders, 282, 1125-1131. https://doi.org/10.1016/j.jad.2020.12.122

Document status and date:

Published: 01/03/2021

DOI:

10.1016/j.jad.2020.12.122

Document Version:

Publisher's PDF, also known as Version of record

\section{Document license:}

Taverne

Please check the document version of this publication:

- A submitted manuscript is the version of the article upon submission and before peer-review. There can be important differences between the submitted version and the official published version of record.

People interested in the research are advised to contact the author for the final version of the publication, or visit the DOI to the publisher's website.

- The final author version and the galley proof are versions of the publication after peer review.

- The final published version features the final layout of the paper including the volume, issue and page numbers.

Link to publication

\footnotetext{
General rights rights.

- You may freely distribute the URL identifying the publication in the public portal. please follow below link for the End User Agreement:

www.umlib.nl/taverne-license

Take down policy

If you believe that this document breaches copyright please contact us at:

repository@maastrichtuniversity.nl

providing details and we will investigate your claim.
}

Copyright and moral rights for the publications made accessible in the public portal are retained by the authors and/or other copyright owners and it is a condition of accessing publications that users recognise and abide by the legal requirements associated with these

- Users may download and print one copy of any publication from the public portal for the purpose of private study or research.

- You may not further distribute the material or use it for any profit-making activity or commercial gain

If the publication is distributed under the terms of Article $25 \mathrm{fa}$ of the Dutch Copyright Act, indicated by the "Taverne" license above, 
Research paper

\title{
Exploring differences in quality of life in clinical populations of depressed outpatients with and without personality disorders
}

\author{
Marit Kool ${ }^{\text {a, }}$, Lotte H.J.M. Lemmens ${ }^{b}$, Puck Hartog ${ }^{\text {a }}$, Rien Van ${ }^{\text {a }}$, Matthijs Blankers ${ }^{c}$, \\ Jaap Peen ${ }^{\mathrm{d}}$, Suzanne C. van Bronswijk ${ }^{\mathrm{b}}$, Jack J.M. Dekker ${ }^{\mathrm{e}}$ \\ ${ }^{a}$ Arkin Mental Health Care, Domselaerstraat 128, 1093 MB Amsterdam, The Netherlands \\ ${ }^{\mathrm{b}}$ Faculty of Psychology and Neuroscience, Section Clinical Psychology, Maastricht University, Maastricht, The Netherlands \\ ${ }^{\mathrm{c}}$ Department of Research, Arkin Mental Health Care, Academic Medical Center, Department of Psychiatry, Amsterdam Institute for Addiction Research, University of \\ Amsterdam, Trimbos Institute - Netherlands Institute of Mental Health and Addiction \\ d Department of Research, Arkin Mental Health Care, The Netherlands \\ ${ }^{\mathrm{e}}$ Department of Research, Arkin Mental Health Care, Department of Clinical Psychology, Vrije Universiteit Amsterdam, The Netherlands
}

\section{A R T I C L E I N F O}

\section{Keywords:}

Quality of life

Health related quality of life

HRQOL

Depression

Personality disorders

\begin{abstract}
A B S T R A C T
Background: Although depression and personality disorders (PDs) often co-occur, less is known about the impact of PDs on health-related quality of life (HRQOL) in patients with depression. This study explores the differences in HRQOL of depressed patients with and without PD.

Methods: Baseline data of 397 patients with depression from two randomised controlled trials were used for this analysis. HRQOL was measured with the EuroQol-5D (EQ-5D). Differences were examined between three groups: patients with 1) depression-only, 2) depression and comorbid PD and 3) PD and comorbid depression. The EQ-5D scores of the groups were compared with linear regression.

Results: HRQOL scores were lower in the depression-only group than the depression + PD group, even though depression severity was higher in patients with PD. HRQOL in the PD \pm depression group did not differ from the other groups. In addition, no associations were found between the type or severity of PD and HRQOL.

Discussion: These findings could indicate that patients with PD are less affected by the impact of depression on HRQOL. In addition, the EQ-5D might not adequately capture the impact of PD on quality of life. Further research is needed to compare the EQ-5D with quality of life instruments that include more life domains.

Limitations: Two study samples are combined, and therefore not designed to compare the three groups directly. Generalisation of the results should be done with caution.

Conclusion: Depressed patients with PD report higher HRQOL than depression-only patients. Although higher HRQOL, patients with PD report more severe depressions than depressed-only patients.
\end{abstract}

\section{Background}

Mood disorders and personality disorders (PDs) often co-occur. In a meta-analysis based on 122 studies, $45 \%$ of patients with major depressive disorder (MDD) and $60 \%$ of patients with what was formerly known as dysthymia also met the criteria for one or more personality disorders. In addition, the severity of the PD has been found to be associated with the duration of depression (Friborg et al., 2014). Both depressive disorders and PDs are highly invalidating conditions that affect the quality of life of patients. For example, in a general population sample in Norway $(N=2065)$ quality of life was studied using various sources of information, including an interview, socio-demographic variables, subjective perceptions of somatic health, and the most common mental disorders. This study indicated that a diagnosis of major depression or dysthymia had a negative effect on quality of life. Furthermore, the presence of any PD was found to be the most important negative determinant of quality of life (Cramer et al., 2007). Nevertheless, the effect of a comorbid PD on the perceived quality of life in depressed patients remains largely unknown.

Health-related quality of life (HRQOL) is a generic concept that

\footnotetext{
* Corresponding author: NPI, Domselaerstraat 128, 1093 MB, Amsterdam, The Netherlands.

E-mail addresses: Marit.Kool@arkin.nl (M. Kool), Lotte.Lemmens@maastrichtuniversity.nl (L.H.J.M. Lemmens), Puck.Hartog@npsai.nl (P. Hartog), Rien.Van@

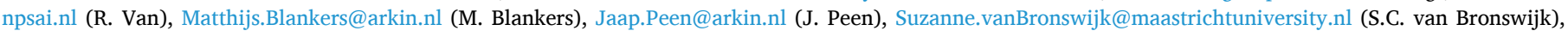
Jack.Dekker@arkin.nl (J.J.M. Dekker).
} 
reflects subjective perceptions and experiences. It can be impaired when a disease or illness leads to functional limitations and perceived difficulties in daily life. Generic instruments are supposed to be suitable for all diseases, making it possible to compare disease burdens in different patient populations. A widely used generic instrument for measuring HRQOL is the EuroQol-5D (EQ-5D) (Brooks et al., 2003; EuroQolGroup, 1990). It can be used to calculate health state index scores ranging from 0 (where 0 is a health state equivalent to death) to 1 (perfect health). However, health state preferences can differ between countries (EuroQol, 2018).

In general populations, mean EQ-5D index scores range from 0.83 to 0.87 (Burstrom et al., 2001; Luo et al., 2005; Saarni et al., 2007). Depression has a substantial impact on HRQOL as is shown by two studies that reported EQ-5D scores between 0.33 and 0.47 in patients with MDD. In both studies EQ-5D index scores were associated with depression severity (Sapin et al., 2004; Sobocki et al., 2007). However, because comorbidity was not specified, it remains unclear whether the index values in these studies were representative for depressed patients with or without comorbid PDs.

In studies focusing on HRQOL in patients with $\mathrm{PD}$, mean index scores of 0.46 - 0.56 were found (Soeteman et al., 2008; van Asselt et al., 2008; Palmer et al., 2006). However, these studies did not specify comorbid disorders such as MDD. In addition, Soeteman et al. (2008) found that the total number of PD diagnoses rather than the specific type of PD determined quality of life.

To our knowledge, only one study has examined differences in HRQOL in patients with (which was formerly known as) axis-I disorders (e.g. anxiety disorders, mood disorders, eating disorders, substance use disorders and somatoform disorders), with and without comorbid PD. They found lower index scores in patients with comorbid diagnoses (EQ$5 \mathrm{D}$ index score $=0.49$ ) than in patients with only axis I (index score $=$ 0.55 ) or axis II diagnoses (index score $=0.61$ ). In addition, a negative association was found between HRQOL and severity of PD, measured by the total number of personality disorder traits (Feenstra et al., 2012). Although only part of the sample were MDD patients with and without PDs and the patient group consisted of adolescents, these findings give some indication of the additional impact of PD on HRQOL in depressed patients. This additional impact on HRQOL could be explained by the nature of PDs, as PDs are characterized by a long-term pattern of problems in a broad range of life areas (American Psychiatric Association, 2013).

The aim of the current study was to explore differences in HRQOL in clinical populations of depressed patients with and without PDs. Patients with both depression and PD were further specified into 1) patients referred for treatment of depression with comorbid $\mathrm{PD}$, and 2) patients referred for treatment of PD with comorbid depression. Although the subgroups have the same clinically assessed diagnoses, they were referred by their General Practitioner for different types of treatment and for different primary reasons, i.e. related to depression or related to PD. We therefore explore these subgroups separately.

We expected to find that higher depression severity and general psychological symptom severity are related to lower quality of life in the total sample. Secondly, we hypothesise that patients with comorbid diagnoses of depression and PD will report lower quality of life than depressed patients without PD. To further address the differences between the groups regarding quality of life, the association between severity and type of PD and quality of life will be determined. In line with others we hypothesise that quality of life is negatively correlated with severity (Feenstra et al., 2012; Soeteman et al., 2008) but not with type of PD (Soeteman et al., 2008).

\section{Methods}

\subsection{Data source}

Data were collected in the context of two randomised clinical trials (the STEPd study and Psychotherapy Dosage (PsyDos) study). A detailed description of sample recruitment, study design, and main outcomes for each trial can be found elsewhere (STEPd - Lemmens et al., 2011, 2015; PsyDos - Kool et al., 2018). The current study drew only on the baseline measures from the two trials.

The STEPd sample (Lemmens et al., 2015) was recruited at the mood disorder unit of the Maastricht Community Mental Health Centre (RIAGG) with the aim of comparing the effects of Cognitive Therapy (CT) and Interpersonal Therapy (IPT) in depressed patients. The sample included 182 outpatients with MDD as their primary diagnosis as confirmed with the Structured Clinical Interview for DSM-IV Axis I disorders (SCID-I; Weertman et al., 2000). The patients were also assessed with the Structured Clinical Interview for DSM-IV Axis II disorders (SCID-II; (Weertman et al., 2000) for the presence of comorbid PDs. A PD was diagnosed in 88 participants. The interviews were performed by a trained evaluator. After the intake assessment, participants were randomly allocated to Cognitive Therapy (CT; $n=76$ ), Interpersonal Therapy (IPT; $n=75$ ), or a Waiting List Condition (WLC; $n=31$ ). For practical reasons, ${ }^{1}$ in the current study, only data from patients assigned to one of the active conditions (CT/IPT; $n=151$ ) were used.

The PsyDos sample (Kool et al., 2018) was recruited from patients at a specialised centre for personality disorders (NPI) in Amsterdam. Participants were patients referred for treatment of a PD who, at time of assessment, also suffered from a depression and/or dysthymic disorder. The study was designed to compare the effect of 25 and 50 individual therapy sessions for Schema Focused Therapy (SFT) and Short-term Psychodynamic Psychotherapy (SPSP). The sample consisted of 246 outpatients, aged 18-65, diagnosed with a current major depressive disorder and/or dysthymic disorder (as confirmed with the Mini International Neuropsychiatric Inventory section A and B (MINI; Sheehan et al., 1998) and one or more $\mathrm{PD}(\mathrm{s})$ (as confirmed with the Dutch-language version of the SCID-II (Weertman et al., 2000) or DSM-5 personality disorders (SCID-5-P; Arntz et al., 2017). The interviews were assessed by trained research assistants.

In both samples, the primary diagnosis (MDD or PD) was determined at time of the intake by a trained and experienced clinician. This was verified by a consultation of multi-disciplinary clinicians. Both samples used the following exclusion criteria: lack of internet access, inadequate mastery of Dutch, bipolar disorder, acute suicide risk, concomitant psychological treatment, an IQ of less than 80, and drugs and/or alcohol abuse/dependency. In the PsyDos study, participants were shown a list of substances (e.g. alcohol, marijuana, opiates, cocaine, amphetamines, sedatives) and were asked if they had used any of these substances in the last three months, how often and the average dosages per day. The STEPd study assessed a semi-structured interview for substance use. Based on the provided information, a clinician decided if substance use disorder was the primary diagnosis for treatment. In that case a participant was excluded. The STEPd study used the following additional exclusion criteria: concomitant pharmacological treatment and chronic depression with a duration of more than five years.

The PsyDos study is approved by The Medical Ethics Committee of VU Amsterdam (registration-number NL55916.029.15), and the STEPd study by The Medical Ethics Committee of Maastricht University. Both studies are registered at the Netherlands Trial Register, part of the Dutch Cochrane centre (NTR5941 and ISRCTN67561918 for PsyDos and STEPd respectively) and in both studies all participants provided written informed consent.

\footnotetext{
${ }^{1}$ We excluded the WLC condition from the analyses. Due to ethical considerations, the 'pre-treatment' measure of the WLC condition was assessed at a different time point than the treatment condition, and therefore comparison was not possible. In line with secondary analyses of the STEPd study, the current study only included the treatment conditions (see Lemmens et al., 2020 for an overview).
} 


\section{Design}

The total sample included depressed participants with or without PD. Participants without a PD were selected from the STEPd sample only. Participants with an additional PD were taken from both STEPd and PsyDos samples. This led to the following three subgroups: 1) Depression only $(n=63), 2)$ depressed patients with comorbid PD $(n=88)$, and 3) PD patients with comorbid depression (or dysthymic disorder) ( $n=$ 246). Fig. 1 demonstrates the groups and the sample from which they were taken.

\section{Measures}

\subsection{Demographic variables}

Demographic variables such as gender, age, education level, and active employment were assessed with questionnaires developed for the two studies.

\subsection{Clinical variables}

The clinical variables adopted were depression severity, general psychiatric symptoms, number of PDs and PD clusters. Depression severity was measured with the Beck Depression Inventory, second edition (BDI-II; Beck et al., 1996). BDI-II scores range from 0 to 63, with higher scores indicating more severe symptoms of depression. A meta-analysis of the BDI-II internal consistency estimates yielded a Cronbach's alpha of 0.86 for psychiatric patients and 0.81 for a non-clinical sample (Beck, Steer \& Carbin, 1988). General psychiatric symptoms were measured with the Brief Symptom Inventory (BSI; (Derogatis and Melisaratos, 1983), with higher scores indicating more severe distress (range $0-212$ ). Internal consistency was estimated $\alpha=.93$ (Franke et al., 2017). The number of PDs and PD clusters were assessed with the SCID-II/5-P semi-structured interviews, after the SCID-screener determined which items or PD diagnoses had to be assessed during the interview. The STEPd study assessed the items in the interview that were positive in the screener. The PsyDos study assessed the PD diagnoses that had a score on the cut-off -1 or higher at the screener. PD was considered to be present if, after the interview, a participant met the number of criteria equal to or higher than the cut-off score for one type of $\mathrm{PD}$, or if a participant fulfilled five or more criteria for different types of $\mathrm{PD}^{1}$ (PD Not Otherwise Specified (NOS)). Originally, this definition of
PD NOS was applied to the PsyDos sample only. In order to make the samples comparable, this definition was later applied to the STEPd sample. The total number of participants with PDs in the STEPd sample is therefore higher in the current study than van Bronswijk et al. (2018) reported when using the same sample. The passive-aggressive PD and the Depressive PD were excluded from the analyses as they are no longer considered as PD in the DSM-IV and DSM-5 because of limited scientific support (American Psychiatric Association, 2000).

\subsection{Health related quality of life}

HRQOL was measured with the EQ-5D (EuroQolGroup, 1990). The EQ-5D includes the following five dimensions: mobility, self-care, usual activities, pain/discomfort, and anxiety/depression. Each dimension has three levels: no problems $(=1)$, some problems $(=2)$, and severe problems $(=3)$. Participants were asked to describe their health state by selecting the most appropriate statement in each dimension to generate a health state profile, 11,213 for example. The selected health states were converted into an EQ-5D summary index between -0.33 (worst imaginable health state) and 1.00 (perfect health state). This index is derived by applying a formula that attaches values (weightings) to each of the levels in each dimension. The weightings are based on a population value set. The Dutch value set (Lamers et al., 2006) was used for the current study. EQ-5D index scores in PD patients differ significantly from those in a non-clinical population (index scores non-clinical $=0.85$ v. $\mathrm{PD}=0.54$ ), indicating a good discriminant validity (Brazier et al., 2014). Index scores correlate moderately $(r=-0.49)$ with the Global Severity Index in a clinical sample with PD, indicating moderate convergent validity (Soeteman et al., 2005).

HRQOL data in the PsyDos sample were collected with the newest version of the EQ-5D, which consists of five levels (EQ-5D-5 L) instead of three. In order to make the dataset comparable with the data from the STEPd sample, the EQ-5D-5 L scores were converted to EQ-5D-3 L scores with the crosswalk provided by the EuroQoL group (EuroQol research foundation, 2019).

\section{Statistical analyses}

\subsection{Between study comparisons}

The two study samples (STEPd and PsyDos) were compared in order to detect the presence of possible confounders. ANOVA was used to

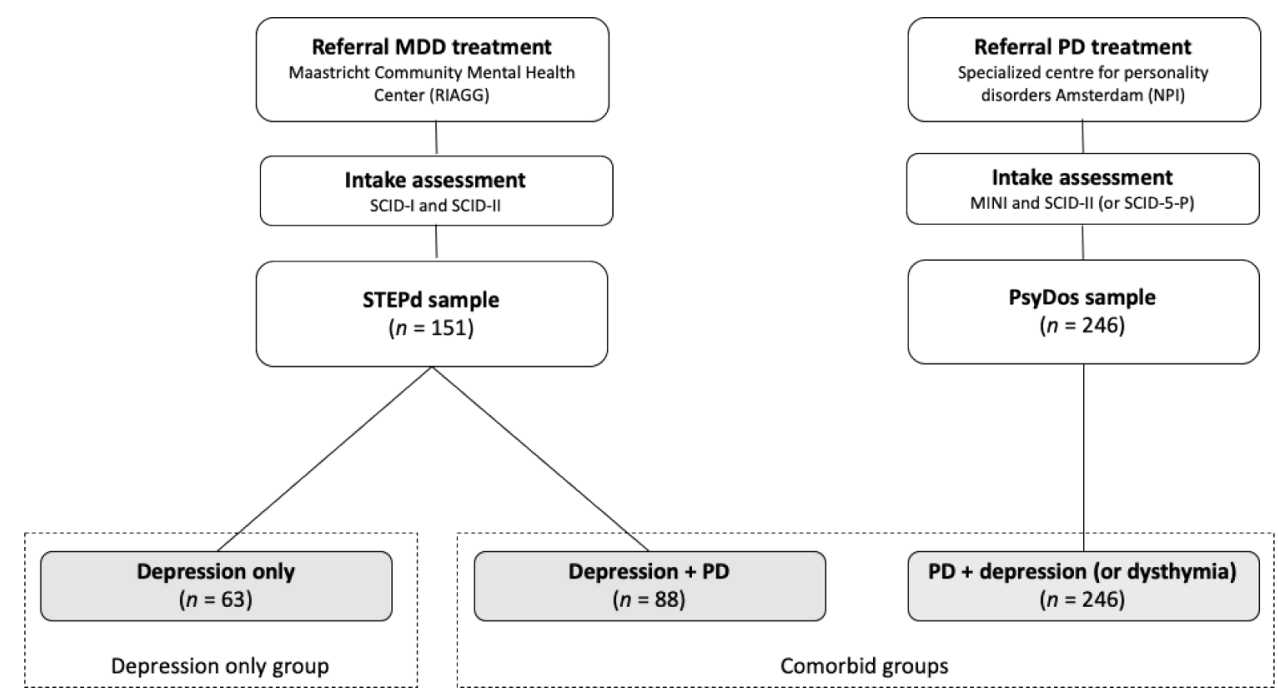

Fig. 1. Overview of the patient flow included in the samples, used in the current study.

SCID-I: Structured Clinical Interview for DSM-IV, Axis I; SCID-II: Structured Clinical Interview for DSM-IV, Axis II; MINI: Mini International Neuropsychiatric Inventory section A and B; SCID-5-P: Structured Clinical Interview for DSM-5, Personality Disorders. 
compare continuous variables (age, BDI-II scores, and BSI scores). Ordinal and dichotomous variables (gender, level of education and active employment) were compared between samples using chi-square tests.

\subsection{Descriptive analyses}

Descriptive and clinical variables were compared between three groups: 1) depression only, 2) depression + PD, and 3) PD + depression. Means for the continuous variables (age, BDI-II scores and BSI scores) were compared using one-way ANOVA analyses and post hoc comparisons with Bonferroni-corrections. Ordinal and dichotomous variables (gender, education, active employment, depression severity, and chronic depression) were compared with Kruskal-Wallis tests with post hoc comparisons with Bonferroni correction. The PD characteristics (PDs, PD clusters and number of PDs) of the comorbid groups (depression $+\mathrm{PD}$ and $\mathrm{PD}+$ depression) were compared using chi-square tests.

\subsection{Health related quality of life}

The mean EQ-5D index scores of the three groups were compared with linear regression for which assumptions were tested (normality, linearity, homoscedasticity, multicollinearity and normality of the residuals). Education level was statistically differing between the three groups, therefore we controlled for this variable. The comorbid samples also differed in PD types, PD clusters and number of PDs. To control for these differences in PD characteristics (in addition to educational level) while limiting the number of extra variables we comprised two PD confounders that summarize the differences: number of PDs (one PD vs two or more PDs) and a dichotomous variable 'only Cluster C' (patients with cluster $C$ vs all other patients). In the comparisons amongst the three groups (depression-only, depression $\pm \mathrm{PD}$ and $\mathrm{PD} \pm$ depression), $p$ values were Bonferroni corrected and a significance level of $0.05 / 3=$ 0.0167 was used.

An additional Pearson correlation between EQ-5D index scores and BDI-II scores was computed to test for a possible association between the variables.

\subsection{Exploratory analyses}

An exploratory analysis was then conducted in which we compared mean EQ-5D index scores for the depression-only group with depressed patients + PD NOS, and depressed patients + other PDs, by using linear regression including educational level as confounder. Moreover, we explored the differences between EQ-5D mean index scores in the PD clusters (B vs C) and the number of PD diagnoses ( 1 vs $\geq 1$ ) using linear regression with educational level as covariate. A significance level of $p \leq .05$ was used.

All analyses were performed in IBM SPSS version 26 .

\section{Results}

\subsection{Between study comparisons}

Differences on all baseline characteristics between the two original samples were checked in order to detect possible confounders. Gender and active employment did not differ between the samples. Patients in the PsyDos sample had a significantly higher level of education $\left(\chi^{2}(2)=\right.$ $31.496, p<.001)$. A lower average age was found in the STEPd sample, although not statistically significant $(F(1395)=3.480, p=.063)$.

\subsection{Descriptive analyses}

The total sample consisted of 397 patients, two-thirds of whom were female $(68 \%)$, with a mean age of 39.8 years $(S D=11.8)$. Mean baseline $\mathrm{BDI}-\mathrm{II}$ scores were in the lower range for a severe depression in the total

sample $(M=30.85)$ and the mean BSI score was above average compared to outpatient populations (De Beurs, 2008). Eighty-four percent of the patients $(N=334)$ had both a depression (MDD and/or dysthymic disorder) and a PD.

Table 1 shows the patient characteristics and scores on the BDI-II and BSI for the three subgroups: the depression-only group, the depression $+\mathrm{PD}$ group and the PD + depression group. No differences between the three groups were found regarding gender or active employment. A trend was found for age $(F(2394)=2.939, p=.054)$. Education level significantly differed amongst the groups. Post hoc analyses indicated a higher mean level of education in the PD + depression group compared to the other groups (depression-only, $p<.001$; depression $+\mathrm{PD}, p<.001$, reflecting the earlier described sample difference).

There were no differences in general psychological symptoms, measured with the BSI between the three groups. However, depression severity (BDI-II) was lower in the depression-only group $(M=27.7$, $S D=8.9)$ compared to the PD + depression group $(M=31.5, S D=10.6$, $p=.020$, Cohen's $d=0.374$ ) and a trend was found when compared to the depression + PD group $(M=31.3, S D=8.8, p=.090$, Cohen's $d=$ 0.404). There were no significant differences in levels of severe depression (BDI-II $>=29$ ) between the groups $(F(2393)=3.547, p=.170$ ).

The number of PDs per patient differed significantly between the two comorbid groups $\left(\chi^{2}(3)=13.77, p=.003\right)$, with more patients in the PD

\section{Table 1}

Patient characteristics, general psychiatric symptom severity, depression severity and personality disorders by patient group.

\begin{tabular}{|c|c|c|c|}
\hline & $\begin{array}{l}\text { Depression } \\
\text { only }^{1} \\
(n=63)\end{array}$ & $\begin{array}{l}\text { Depression }+ \\
\mathrm{PD}^{1} \\
(n=88)\end{array}$ & $\begin{array}{l}\mathrm{PD}+ \\
\text { depression } \\
(n=246)\end{array}$ \\
\hline \multicolumn{4}{|l|}{ Demographics: } \\
\hline Female, $n(\%)$ & $43(68.3 \%)$ & $57(64.8 \%)$ & $170(69.4 \%)$ \\
\hline Age in years, mean (SD) & $43.00(11.27)$ & $40.00(12.50)$ & 38.96 (11.69) \\
\hline \multicolumn{4}{|l|}{ Education, $n(\%)$} \\
\hline Low & $12(19 \%)$ & $17(19.3 \%)$ & $14(6.1 \%)$ \\
\hline Medium & $35(55.6 \%)$ & $61.4 \%)$ & $108(7.2 \%)$ \\
\hline High & $16(25.4 \%)$ & $17(19.3 \%)$ & $107(46.7)$ \\
\hline $\begin{array}{l}\text { Active employment, yes, } n \\
\quad(\%)\end{array}$ & $37(58.7 \%)$ & $53(60.9 \%)$ & $142(57.7 \%)$ \\
\hline \multicolumn{4}{|l|}{$\begin{array}{l}\text { General psychological } \\
\text { distress }\end{array}$} \\
\hline BSI score, mean (SD) & $68.98(30.67)$ & $77.15(32.72)$ & $79.40(36.32)$ \\
\hline \multicolumn{4}{|l|}{ Depression specifiers } \\
\hline BDI-II score, mean (SD) & $27.68(8.92)$ & $31.26(8.80)^{*}$ & $\begin{array}{l}31.52 \\
(10.59)^{* * *}\end{array}$ \\
\hline $\begin{array}{l}\text { Severe depression }^{\mathrm{a}}, n(\%) \\
\text { PD specifiers }\end{array}$ & \multicolumn{2}{|c|}{ PD specifiers } & $145(59.9 \%)$ \\
\hline$\geq 2$ PD diagnoses, $n(\%)$ & 0 & $11(12.5 \%)$ & $73(30.4 \%)^{*}$ \\
\hline Cluster A, $n(\%)$ & 0 & $7(8.0 \%)$ & $26(10.6 \%)$ \\
\hline Paranoid & 0 & $4(4.5 \%)$ & $23(9.3 \%)$ \\
\hline Schizotypal & 0 & $2(2.3 \%)$ & $1(0.4 \%)$ \\
\hline Schizoid & 0 & $1(1.1 \%)$ & $3(1.2 \%)$ \\
\hline Cluster B, $n(\%)$ & 0 & $6(6.8 \%)^{* *}$ & $73(29.7 \%)^{* *}$ \\
\hline Theatrical/histrionic & 0 & $0(0.0 \%)$ & $1(0.4 \%)$ \\
\hline Borderline & 0 & $4(4.5 \%)^{* *}$ & $63(25.6 \%)^{* * *}$ \\
\hline Narcissistic & 0 & $2(2.3 \%)$ & $13(5.3 \%)$ \\
\hline Antisocial & 0 & $0(0.0 \%)$ & $1(0.4 \%)$ \\
\hline Cluster C, $n(\%)$ & 0 & $46(52.3 \%)$ & $150(61.0 \%)$ \\
\hline Avoidant & 0 & $29(33.0 \%)^{*}$ & $106(43.1 \%)^{*}$ \\
\hline Dependant & 0 & $1(1.1 \%)$ & $11(4,5 \%)$ \\
\hline Obsessive compulsive & 0 & $20(22.7 \%)$ & $70(28.5 \%)$ \\
\hline PD NOS, $n(\%)$ & 0 & $38(43.2 \%)^{* *}$ & $60(24.4 \%)^{* *}$ \\
\hline \multicolumn{4}{|c|}{$\begin{array}{l}2 \text { Kool et al., 2018. BSI= Brief Symptom Inventory (De Beurs, 2008); mean TOT = mean total score } / 5 \\
\text { tems; BDI-II = Beck Depression Inventory, second edition (Beck et al., 1996); PD NOS= personalit } \\
\text { disorder, not otherwise specified. }\end{array}$} \\
\hline \multicolumn{4}{|c|}{$\begin{array}{l}* \text { The mean difference is significant at the } 0.05 \text { level. } \\
\text { * The mean difference is a trend at the } 0.10 \text { level.Considering the significan } \\
\text { differences in BDI-II mean scores, the depression-only group was used as th } \\
\text { eference group. }\end{array}$} \\
\hline
\end{tabular}


+ depression group suffering from more than one PD diagnosis $(30 \%)$ than in the depression + PD group (13\%). Furthermore, there were more cluster B PDs in the PD + depression group ( $30 \%$ v. $7 \%, \chi^{2}(1)=18.75$, $p<.000)$, in particular the number of borderline PD diagnoses $(26 \% \mathrm{v}$. $\left.5 \%, \chi^{2}(1)=17.93, p<.001\right)$. The depression + PD group had more PD Not Otherwise Specified (PD NOS) ( $43 \%$ v. $\left.24 \%, \chi^{2}(1)=11.04, p=.001\right)$ than the PD + depression group. Patients diagnosed with a PD NOS reported lower depression severity than those with other PDs $(F(1328)=4.35$, $p=.038$ )

\subsection{Health related quality of life}

A mean EQ-5D index score of $0.60(S D=0.23)$ was found for the total sample. In addition, we found a negative correlation between HRQOL and depression severity $(r(355)=-0.379, p<.001)$ indicating that higher levels of depression are related to lower HRQOL. Although depression severity was higher in the comorbid group (depression + PD and PD + depression taken together) than in the depression-only group, we found higher HRQOL scores in the comorbid group $(M=0.617, S D=0.23)$ than in the depressed group $(M=0.533, S D=0.26 ; B=0.084, t(338)=2530$, $p=.012$ ).

Table 2 shows the HRQOL index scores and mean item scores for the three separate groups. Linear regression analysis indicated that when controlled for education level, number of PDs, and cluster C PD, lower HRQOL scores were found in the depression-only group $(M=0.533$, $S D=0.26)$ than in the depression + PD group $(M=0.640, S D=0.24, B=$ $0.109, t(337)=2788, p=.006$, Cohen's $d=0.434)$. No differences were found between the depression-only group and the PD \pm depression group ( $p=.045$; due to Bonferroni correction a significance level of $p=.0167$ was used), and between the two comorbid groups, when controlling for educational level, number and type of PD.

To explore which items contributed to the differences, the EQ-5D scores were compared at the item level. There were no differences in the impact of mobility, self-care, usual activities or anxiety/depression on quality of life between the three groups. Reported impact of pain/

Table 2

EQ-5D index scores and mean item scores for the three groups controlled for education, number and type of PD.

\begin{tabular}{|c|c|c|c|c|c|c|}
\hline & \multicolumn{2}{|c|}{$\begin{array}{l}\text { Depression only }{ }^{1} \\
(n=63)\end{array}$} & \multicolumn{2}{|c|}{$\begin{array}{l}\text { Depression }+\mathrm{PD}^{1} \\
(n=88)\end{array}$} & \multicolumn{2}{|c|}{$\begin{array}{l}\mathrm{PD}+\text { depression }^{2} \\
(n=246)\end{array}$} \\
\hline & $\begin{array}{l}\text { Index } \\
\text { score }\end{array}$ & $\begin{array}{l}\text { Mean } \\
\text { item } \\
\text { score }\end{array}$ & $\begin{array}{l}\text { Index } \\
\text { score }\end{array}$ & $\begin{array}{l}\text { Mean } \\
\text { item } \\
\text { score }\end{array}$ & $\begin{array}{l}\text { Index } \\
\text { score }\end{array}$ & $\begin{array}{l}\text { Mean } \\
\text { item } \\
\text { score }\end{array}$ \\
\hline $\begin{array}{l}\text { Quality of life } \\
\text { (EQ5D-3 L } \\
\text { index score) }\end{array}$ & $\begin{array}{l}.53 \\
(0.26) \\
*\end{array}$ & & $\begin{array}{l}.64 \\
(0.24) \\
*\end{array}$ & & $\begin{array}{l}.61 \\
(0.22)\end{array}$ & \\
\hline Mobility & & $\begin{array}{l}1.24 \\
(0.43)\end{array}$ & & $\begin{array}{l}1.18 \\
(0.42)\end{array}$ & & $\begin{array}{l}1.19 \\
(0.40)\end{array}$ \\
\hline Self-care & & $\begin{array}{l}1.08 \\
(0.27)\end{array}$ & & $\begin{array}{l}1.08 \\
(0.27)\end{array}$ & & $\begin{array}{l}1.10 \\
(0.30)\end{array}$ \\
\hline $\begin{array}{l}\text { Usual } \\
\text { activities }\end{array}$ & & $\begin{array}{l}2.00 \\
(0.54)\end{array}$ & & $\begin{array}{l}1.86 \\
(0.51)\end{array}$ & & $\begin{array}{l}1.88 \\
(0.56)\end{array}$ \\
\hline $\begin{array}{l}\text { Pain/ } \\
\text { discomfort }\end{array}$ & & $\begin{array}{l}1.89 \\
(0.54)^{*}\end{array}$ & & $\begin{array}{l}1.76 \\
(0.57)\end{array}$ & & $\begin{array}{l}1.61 \\
(0.55)^{*}\end{array}$ \\
\hline $\begin{array}{l}\text { Anxiety/ } \\
\text { depression }\end{array}$ & & $\begin{array}{l}2.13 \\
(0.64)\end{array}$ & & $\begin{array}{l}1.97 \\
(0.54)\end{array}$ & & $\begin{array}{l}2.15 \\
(0.48)\end{array}$ \\
\hline
\end{tabular}

${ }^{1}$ Lemmens et al., 2015.

2 Kool et al., 2018.

Note: EQ-5D-3 $L=$ EuroQol 5 dimensions, 3 response categories (EuroQolGroup, 1990); PD = Personality Disorder; Index score refers to a summary index ranging from -0.33 (worst imaginable health state) to 1.00 (best imaginable health state). Index scores are derived from the five item scores, with a weighting for each response level in each dimension and on the basis of the value set for the Dutch population (Lamers et al., 2006). Mean item score refers to the reported health state for each dimension, with higher item scores reflecting lower health states; * The mean difference between the groups is significant at the 0.05 level. discomfort was seen less in patients with PD and depression $(M=1.61$, $S D=0.55 \mathrm{pain} /$ discomfort item score) than in depression-only patients $(M=1.89, S D=0.54 ; B=-0.251, t(337)=-3055, p=.002)$.

\subsection{Exploratory analyses}

Further analyses are performed to better understand the findings in the comorbid groups. The comorbid groups show a higher HRQOL (EQ5D) and also a higher depression severity (BDI-II), while the sample as a whole showed a negative relation between depression severity (BDI-II) and HRQOL.

First, we checked whether the higher depression severity in the comorbid groups (especially in the PD + depression group) could also be found on the BSI subscale depression. This was partially the case; we found higher levels of depression subscale scores in the PD + depression group than in the depression-only group $(B=0.465, t(342)=3527$, $p \leq .001)$. Secondly, we looked into the relation between mild, moderate and severe depression (BDI-II) on the EQ-5D item anxiety/depression. As expected, for the whole sample, a pattern of higher depression severity was related to higher scores on the anxiety/depression item of the EQ5D $\left(\chi^{2}(4)=42,401, p<.001\right)$. However, when analysed per group, mild and moderate depressions in the depression-only group also showed substantial impact on the anxiety/depression item of the EQ-5D, in contrast with the comorbid groups. This would indicate that in the depression-only group, patients with less and less severe depression symptoms, experience more burden from their depression and anxiety on their HRQOL.

Furthermore, differences in HRQOL were explored between the different PD diagnoses (Table 3). No differences were found in reported HRQOL between cluster-B and cluster-C PDs. In addition, differences in HRQOL between patients with a depression, patients with a PD NOS and patients with other PD(s) were explored. Patients with a PD NOS had significantly higher quality of life index scores $(M=0.6506, S D=0.23)$ than depressed patients without $\mathrm{PD}(M=0.5330, S D=0.26, B=0.123, t$ $(337)=3155, p=.002)$. No differences were found between depressed patients and patients with other PDs or between patients with a PD NOS and patients with other PDs. As for the relationship between severity of PD and HRQOL, we found no significant relation between the number of PD diagnoses per patient ( 1 vs $>=1$ ) and EQ-5D index scores.

\section{Discussion}

In this paper we aimed to explore the differences in HRQOL between clinical populations of depressed outpatients with and without PD. Three groups were compared: depression-only, depression $+\mathrm{PD}$, and PD + depression. In contrast to our hypotheses, patients in the depression-only group reported a lower quality of life compared to patients who suffered from comorbid diagnoses of depression and PD. When subdividing the comorbid group, this difference was statistically significant for the depression + PD group, but not for the PD +

Table 3

Mean EQ-5D index scores for different types of PDs and number of PD diagnoses.

\begin{tabular}{ll}
\hline & Mean index score (SD) \\
\hline Cluster B & $.58(0.24)$ \\
Cluster C & $.61(0.22)$ \\
PD NOS & $.65(0.23)$ \\
Number of PD diagnoses & \\
1 & $.62(0.23)$ \\
2 & $.61(0.25)$ \\
3 & $.60(0.21)$ \\
4 & $.60(0.13)$ \\
5 & .37 \\
\hline
\end{tabular}

NB. Only one participant was assessed with five PDs. Therefore, standard deviation (SD) did not apply. 
depression group. These findings contradict the results of Feenstra et al. (2012) who found lower quality of life scores in a comorbid group of clinical disorder and PDs than in non-comorbid groups.

The two samples that were combined for this study were checked for differences in baseline characteristics. Education level, type of PD and number of PD diagnoses were found to be significant confounders and were controlled for in analyses.

As expected, levels of depression were higher in patients in the two comorbid groups than in the depression-only group with a BDI-II total score difference of 3.8 (Cohen's $d=0.39$ ). Although this is a statistically significant finding, the clinical relevance of a 3.8 points difference can be discussed (Hiroe et al., 2005). Considering PDs, more patients in the PsyDos sample had cluster-B PDs and had more than one PD than in the STEPd sample. This may be considered in line with the differences in treatment focus between the institutions: for the STEPd sample primarily depression, and for the PsyDos sample primarily PD.

No correlation was found between general psychological symptoms and quality of life for the sample as a whole. As expected, the level of depression was negatively correlated with quality of life, indicating that more severe depression is linked to lower quality of life. This is in line with previous research which has reported a substantial impact of depression on quality of life and an inverse relation between quality of life and depression severity (Sapin et al., 2004; Sobocki et al., 2007).

In contrast to our main hypothesis, in general, patients with depression and PD (STEPd and PsyDos samples taken together) reported higher quality of life compared to patients who suffered from depression only. A possible explanation for this, although speculative, might be that PD patients are less impacted in quality of life caused by their depression symptoms because they have experienced more adverse events throughout their lives, which could have made them more resilient to new difficulties they encounter.

Another possibility is that the quality of life instrument (EQ-5D) does not adequately capture the specific impact of PD on quality of life. As the EQ-5D is a generic instrument, it cannot be as sensitive as a diagnosisspecific instrument in terms of addressing all the aspects of quality of life for every patient group (Sanderson and Andrews, 2002). PDs are characterized by problems in a broad range of areas, such as cognition, affectivity, interpersonal functioning and impulse control. The EQ-5D includes the five dimensions (as mentioned in the Methods section) that do not directly measure the problematic areas of PDs. The exploratory findings support this hypothesis, showing no significant association between number of PD diagnoses and EQ-5D index scores. The impact of PDs on quality of life is not sufficiently captured in the EQ-5D scores. There has been little research on the usefulness of the EQ-5D in PD samples. A study by van Asselt et al. (2009) showed that it is quite responsive for treatment improvement in borderline personality disorder (BPD). However, several studies also report remarkable discrepancies between clinical improvement in BPD patients and improvement in EQ-5D scores (Blankers et al., 2019; van Asselt et al., 2008). When quality of life was studied in a broader approach by Cramer et al. (2007), the presence of a PD appeared to be the strongest negative predictor of quality of life. This could indicate that a broader approach to measuring quality of life is needed in order to address the impact of PD on quality of life adequately.

When taking a closer look at the two subgroups of patients with PD, only the depression \pm PD group differed significantly from the depression only group. This might possibly be a result of the different samples used for this study. Furthermore, it should be noted that the difference in HRQOL scores between the two comorbid groups was rather small and therefore questioned to be clinically relevant.

Finally, we hypothesized that, not the type of PD would impact HRQOL, but the severity would. In line with our expectations, no differences in HRQOL were found between cluster B and C PDs in our study, confirming other research (Soeteman et al., 2008; Jackson and Burgess, 2004), indicating a comparable impact of cluster B and C PDs on quality of life. Contrary to our expectations, no differences in HRQOL were found for the number of PD diagnoses. This contrasts with several studies showing a relationship between the number of PDs (or PD traits) and quality of life (Soeteman et al., 2008; Jackson and Burgess, 2004; Nakao et al., 1992; Feenstra et al., 2012). Only one other study did not confirm this relation (Narud et al., 2005) and attributed that to a small sample size.

A strength of this study is that, to our knowledge, it is the first study to explore differences in quality of life in clinical samples of adult depressed patients with and without PD. The same HRQOL instrument was used in a large number of patients. This study contributes to the scarce evidence available on HRQOL in mental health samples and raises the issue of the reliability of the EQ-5D as an instrument for PD patients. More specifically, it sheds more light on the differences (or the absence thereof) between depressed patients with and without PD.

\subsection{Limitations}

Besides these strengths, an important limitation is that two samples, that were not primarily designed to research the current research questions, were combined. As a consequence, the samples differed in terms of known factors (such as educational level, region, time) and unknown factors that could be sources of variation. Although we controlled for the known factors (level of education, type and number of PDs), risk of other biases remains. For example, the STEPd sample excluded patients who used antidepressant medication at baseline, the PsyDos sample did not. A depressive episode of more than five years was an exclusion criterion in the STEPd sample, but not in the PsyDos sample. Moreover, there were differences between the institutions and in referral patterns as well as possible differences between interview assessors in terms of their experience, education and primary focus (on depression or PD). Because of these potential sample biases, we should be cautious about the generalisation of our results. Nevertheless, the main finding that quality of life is lower in depressed patients than in patients with depression and PD was not only found for the total comorbid sample but also in the STEPd sample alone (depression-only group v. depression + PD group). That indicates that this finding not only demonstrates a difference in the sample but also a possible difference between patient groups with and without PD.

In the comorbid groups, a substantial part of the participants had a cluster-C or PD NOS diagnosis. As shown in Table 3, participants with these diagnoses had higher mean HRQOL scores than participants with a cluster B diagnosis (although not statistically significant), resulting in higher HRQOL scores in the PD sample. Another limitation is that the current study did not assess clinical comorbidities, other than depression. Therefore, we do not know whether other diagnoses were present in our sample and what their possible impact on HRQOL is.

\section{Conclusion}

This study examined HRQOL in samples of depressed patients with and without PD. We conclude that depressed patients without PDs report lower HRQOL than patients with PD, which could indicate that patients with PD are more resilient for the impact of depression on their HRQOL. However, it could also reflect that the instrument used to measure HRQOL may not capture the impact of personality pathology on quality of life adequately, which is usually found in domains as cognition, affectivity, interpersonal functioning and impulse control. More research is needed to investigate whether the EQ-5D is the best HRQOL instrument for PD patients, by comparing it to other quality of life instruments such as the Short Form Health Survey 36 (SF-36; Aaronson et al., 1998) or The World Health Organization Quality of Life (WHOQOL; World Health Organization, 1996).

\section{Declaration of Competing Interest}

None. 
This research did not receive any specific grant from funding agencies in the public, commercial, or not-for-profit sectors.

\section{Statement}

M. Kool, L. Lemmens and P. Hartog designed the study. M. Kool and P. Hartog managed the literature searches and wrote the drafts of the manuscript. J. Peen undertook the statistical analysis. R. Van and J. Dekker supervised the study. L. Lemmens, M. Blankers and S. van Bronswijk commented on the drafts of the manuscript. All authors contributed to and have approved the final manuscript.

\section{Acknowledgement}

None.

\section{References}

Aaronson, N.K., Muller, M., Cohen, P.D., Essink-Bot, M.L., Fekkes, M., Sanderman, R., Sprangers, M.A., te Velde, A., Verrips, E., 1998. Translation, validation and norming of the Dutch language version of the SF-36 Health Survey in community and chronic disease populations. J. Clin. Epidemiol. 51, 1055-1068.

American Psychiatric Association, 2013. Diagnostic and Statistical Manual of Mental Disorders, 5th ed. Author, Arlington, VA.

American Psychiatric Association, 2000. Diagnostic and Statistical Manual of Mental Disorders, 4th ed. Author, Washington, DC. Text Revision.

Arntz, A., Kamphuis, J.H., Derks, J., 2017. Structured Clinical Interview For DSM-5 Personality disorders (SCID-5-P). The Netherlands: Boom uitgevers Amsterdam, Amsterdam.

Beck, A.T., Steer, R.A., Brown, G.K., 1996. Beck Depression Inventory-II: Manual. Harcourt Brace, Boston.

Beck, AT, Steer, R.A., Carbin, M.G., 1988. Psychometric properties of the Beck Depression Inventory: Twenty-five years of evaluation. Clinical Psychology Review 8 (1), 77-100.

Blankers, M., Koppers, D., Laurenssen, E.M.P., Peen, J., Smits, M.L., Luyten, P., . . ., Dekker, J.J.M., 2019. Mentalization-based treament versus specialist treatment as usual for borderline personality disorder: economic evaluation alongside a randomized controlled trial with 36-month follow-up. J. Pers. Disord. 1-20.

Brazier, J., Connell, J., Papaioannou, D., et al., 2014. A systematic review, psychometric analysis and qualitative assessment of generic preference-based measures of health in mental health populations and the estimation of mapping functions from widely used specific measures. Chapter 3, Assessing the psychometric performance of the EQ-5D and SF- 6D using existing data sets. Health Technol. Assess (Rockv) 18, 34 Available from: https://www.ncbi.nlm.nih.gov/books/NBK262026/.

Brooks, R., Rabin, R., de Charro, F., 2003. The Measurement and Valuation of Health Status Using EQ-5D: a European perspective. Kluwer Academic Publishers, London.

Burstrom, K., Johannesson, M., Diderichsen, F., 2001. Swedisch population health related quality of life results using the EQ-5D. Qual. Life Res. 10 (7), 621-635.

Cramer, V., Torgerson, S., Kringlen, E., 2007. Socio-demographic conditions, subjective somatic health, axis I disorders and personality disorders in the common population: the relationship to quality of life. J. Pers. Disord. 21 (5), 552-567.

de Beurs, E., 2008. Brief Symptom Inventory Handleiding. Leiden: The Netherlands: PITS B. V. Copyright 1975, 2006. Leonard Derogatis. All rights reserved.

Derogatis, L.R., Melisaratos, N., 1983. The Brief Symptom Inventory: an introductory report. Psychol. Med. 13, 10.

EuroQol research foundation, 2018. EQ-5D-3 L User Guide. Basic information On How to Use the EQ-5D-3 L Instrument. Version 6.0. Available from: https://euroqol. org/publications/user-guides.

EuroQol research foundation. (2019). EQ-5D-5 L Crosswalk Index Value Calculator. Available from: https://euroqol.org/eq-5d-5l-about/valuation-standard-value-sets crosswalk-index-value-calculator/.

EuroQolGroup., 1990. EuroQol - a new facility for the measurement of health-related quality of life. Health Policy (New York) 16 (3), 199-208.

Feenstra, D.J., Hutsebaut, J., Laurenssen, E.M.P., Verheul, R., Busschbach, J.J., Soeteman, D.I, 2012. The burden of disease among adolescents with personality pathology: quality of life and costs. J. Pers. Disord. 26 (4), 593-604.

Franke, G.H, Jaeger, S., Glaesmer, H., Barkmann, C., Petrowski, K., Braehler, E., 2017. Psychometric analysis of the brief symptom inventory 18 (BSI-18) in a representative German sample. BMC medical research methodology 17 (1), 14. https://doi.org/10. 1186/s12874-016-0283-3.

Friborg, O., Martinsen, E.W., Martinussen, M., Kaiser, S., Overgard, K.T., Rosenvinge, J. H., 2014. Comorbidity of personality disorders in mood disorders: a meta-analytic review of 122 studies from 1988 to 2010. J. Affect. Disord. 152, 1-11. https://doi. org $/ 10.1016 /$ j.jad.2013.08.023.

Hiroe, T, Kojima, M, Yamamoto, I, Nojima, S, Kinoshita, Y, Hashimoto, N, Watanabe, N, Maeda, T, Furukawa, T.A, 2005. Gradations of clinical severity and sensitivity to change assessed with the Beck Depression Inventory-II in Japanese patients with depression. Psychiatry Research 135 (3), 229-235.

Jackson, H.J., Burgess, P.M., 2004. Personality disorders in the community: results from the Australian National Survey of mental health and wellbeing part III. Soc. Psychiatry Psychiatr. Epidemiol. 39 (10), 765-776.

Kool, M., Van, H.L., Bartak, A., de Maat, S.C.M., Arntz, A., van den Eshof, J.W., . . ., Dekker, J.J.M., 2018. Optimizing psychotherapy dosage for comorbid depression and personality disorders (PsyDos): a pragmatic randomized factorial trial using schema therapy and short-term psychodynamic psychotherapy. BMC Psychiatry 18 (1), 252. https://doi.org/10.1186/s12888-018-1829-1.

Lamers, L.M., McDonnell, J., Satlmeier, P.F.M., Krabbe, P.F.M., Busschbach, J, 2006. The Dutch tariff: results and arguments for an effective design for national EQ-5D valuation studies. Health Econ. 15 (10), 1121-1132.

Lemmens, L.H.J.M., Arntz, A., Peeters, F.P.M.L., Hollon, S.D., Roefs, A., Huibers, M.J.H, 2011. Effectiveness, relapse prevention and mechanisms of change of cognitive therapy vs. interpersonal therapy for depression: study protocol for a randomised controlled trial. Trials 12 (1), 150. Retrieved from. http://www.trialsjournal.com/c ontent/12/1/150.

Lemmens, L.H.J.M., Arntz, A., Peeters, F.P.M.L., Hollon, S.D., Roefs, A., Huibers, M.J.H, 2015. Clinical effectiveness of cognitive therapy v. interpersonal psychotherapy for depression: results of a randomized controlled trial. Psychol. Med. 45 (10), 2095.

Lemmens, L.H.J.M., van Bronswijk, S.C., Peeters, F.P.M.L., Arntz, A., Roefs, A., Hollon, S. D., DeRubeis, R.J., Huibers, M.J.H, 2020. Interpersonal psychotherapy versus cognitive therapy for depression: how they work, how long, and for whom - key findings from an RCT. Am. J. Psychother. 7 (1), 8-14.

Luo, N., Johnson, J.A., Shaw, J.W., Feeny, D., Coons, S.J., 2005. Self-reported health status of the general adult U.S. population as assessed by the EQ-5D and health utilities index. Med. Care 43 (11), 1078-1086.

Nakao, K., Gunderson, J.G., Phillips, K.A., 1992. Functional impairment in personality disorders. J. Pers. Disord. 6 (1), 24-33.

Narud, K., Mykletun, A., Dahl, A., 2005. Quality of life in patients with personality disorders seen at an ordinary psychiatric outpatient clinic. BMC Psychiatry 5 (1), 10.

Palmer, S., Davidson, K., Tyrer, P., Gumley, A., Tata, P., Norrie, J., . . ., Seivewright, H., 2006. The cost-effectiveness of cognitive behavior therapy for borderline personality disorder: results from the Boscot trial. J. Pers. Disord. 20 (5), 466-481.

Saarni, S.I., Suvisaari, J., Sintonen, H., Koskinen, S., Härkänen, T., Lönnqvist, J., 2007. The health-related quality-of-life impact of chronic conditions varied with age in general population. J. Clin. Epidemiol. 60 (12), 1288-e1281.

Sanderson, K., Andrews, G., 2002. Prevalence and severity of mental health-related disability and relationship to diagnosis. Psychiatr. Serv. 53 (1), 80-86.

Sapin, C., Fantino, B., Nowicki, M.L., Kind, P., 2004. Usefulness of EQ-5D in assessing health status in primary care patients wiht major depressive disorder. Health Qual. Life Outcomes 2 (1), 20. Retrieved from. http://www.hqlo.com/content/2/1/20.

Sheehan, DV, Lecrubier, Y, Sheehan, KH, Amorim, P, Janavs, J, Weiller, E, et al., 1998. International Neuropsychiatric Interview (M.I.N.I.): the development and validation of a structured diagnostic psychiatric interview for DSM-IV and ICD-10. J Clin Psychiatry 59 (20:22-33), 4-57.

Sobocki, P., Ekman, M., Agren, H., Krakau, I., Runeson, B., Martensson, B., Jonsson, B., 2007. Health-related quality of life measured with EQ-5D in patients treated for depression in primary care. Value Health 10 (2), 153-160. https://doi.org/10.1111/ j.1524-4733.2006.00162.x.

Soeteman, D.I., Timman, R., Trijsburg, R.W., Verheul, R., 2005. Assessment of the burden of disease among inpatients in specialized units that provide psychotherapy. Psychiatr. Serv, 56 (9), 1153-1155.

Soeteman, D.I., Verheul, R., Busschbach, J., 2008. The burden of disease in personality disorders: diagnosis-specific quality of life. J. Pers. Disord. 22 (3), 259-268.

van Asselt, A.D., Dirksen, C.D., Arntz, A., Giesen-Bloo, J.H., Severens, J.L., 2009. The EQ5D: a useful quality of life measure in borderline personality disorder? Eur. Psychiatry 24 (2), 79-85. https://doi.org/10.1016/j.eurpsy.2008.11.001.

van Asselt, A.D., Dirksen, C.D., Arntz, A., Giesen-Bloo, J.H., van Dyck, R., Spinhoven, P., . . . Severens, J.L., 2008. Out-patient psychotherapy for borderline personality disorder: cost-effectiveness of schema-focused therapy v. transference-focused psychotherapy. Br. J. Psychiatry 192 (6), 450-457. https://doi.org/10.1192/bjp. bp.106.033597.

van Bronswijk, S.C., Lemmens, L.H., Viechtbauer, W., Huibers, M.J., Arntz, A., Peeters, F. P., 2018. The impact of personality disorder pathology on the effectiveness of cognitive therapy and interpersonal psychotherapy for major depressive disorder. J. Affect. Disord. 225, 530-538.

Weertman, A., Arntz, A., Kerkhofs, M.L.M., 2000. Gestructureerd Klinisch Interview Voor DSM-IV As-II Persoonlijkheidsstoornissen (SCID-II). Swets Test Publishers, Lisse.

World Health Organization. Division of Mental Health, 1996. WHOQOL-BREF: Introduction, Administration, Scoring and Generic Version of the Assessment: Field Trial Version. World Health Organization. December 1996. https://apps.who.int/iris /handle/10665/63529. 